RESEARCH REVIEW

\title{
An Analysis of Management of regional development in Iran
}

\section{Mohammad Reza Ghaderi ${ }^{8}$,Masoud Taghvaei ${ }^{9}$, Sirous Shafaghi ${ }^{10}$}

\begin{abstract}
In countries such as Iran which cover a large geographical area, the issue of inequality and regional differences provide a substantial challenge in the effort to achieve balanced development. In this study, data were collected using documentary and survey methods as well as Delphi techniques, and analysis was carried out by combining qualitative and quantitative models. In the second step of the Delphi technique, a study of the impact of the factors on each other, and on Management of regional development in Iran, was made using the cross-impact method. In the final step, the effective factors contributing to Management of regional development in Iran were studied using analytical techniques and MicMac software. After analyzing the impact rate of the effective factors on regional imbalances, the key factors were identified and, finally, solutions to reduce the regional imbalances in Iran were proposed.
\end{abstract}

KEY WORDS: Management of Regional Development, Region, Regional Imbalances

JEL: R23, J11

UDC: 005.52:332.1(55)

005.412:334.7

COBISS.SR-ID 238308108

\footnotetext{
${ }^{8}$ Shakhespajouh Research Institute, Isfahan, Iran, e-mail: Mghaderi373@gmail.com

${ }^{9}$ University of Isfahan, Isfahan, Iran, e-mail: m.taghvaei@geo.ui.ac.ir

${ }^{10}$ Shakhespajouh Research Institute, Isfahan, Iran
} 


\section{INTRODUCTION}

Regional management can be known as a process through which challenges and regional issues are recognized by activities of regional managers, and decisions are made to solve these problems and limitations or in order to regional development (Bauer et al., 2007).

Disparities in the provision of goods and services have been the concern of various regional development proponents. Among the issues that need to be addressed by regional initiatives and policies are accessibility and mobility levels between urban and rural populations (Ponrahono et al., 2015).

Despite the wealth of human and natural resources, Iran still suffers from high levels of inequality and poverty, and is one of the developing countries where there are still significant differences between regions. While poverty has decreased in the cities, in the rural areas poverty, unemployment, and inequality are growing. Such regions are increasingly marginalized from national development. For more than two decades, therefore, policy-makers, planners, and experts have been focusing on spatial and land use planning, economic development, and growth policies as a means to alleviate poverty and minimize inequalities between regions (Ramezani, 1997).

Knowledge of the spatial organization of a region and the factors that cause regional inequalities can lead to an understanding of the policies needed to make development in that region possible. In this study, the capabilities and limitations in Iran have been identified by studying the spatial organization of this region. After considering the factors that underlie the imbalances, suggestions are proposed as to how these imbalances could be reduced.

\section{LITERATURE REVIEW}

Regional imbalances, or regional inequalities, are one of the main problems for policy-makers in many parts of the world, Hence for policy makers, reducing regional disparity may be part of a more general social objective to reduce overall inequality, and in particular inequality between individuals (DuPont, 2007). The problems, which include distribution of income and economic opportunities and activities at both the national and international levels, have continued despite globalization and the ensuing economic growth over the seven decades since the end of World War II. Despite overall growth throughout the world, inequalities still exist, with many areas in underdeveloped countries still suffering from regional imbalances (Petrakos, Saratsis, 2000). There are a number of perspectives on regional planning, such as the Perroux growth pole theory, which suggests that development is not uniform, or balanced, over an entire region but tends to cluster around a central area or pole. The proponent of this theory believed that macro investments in large urban areas cause the growth of the central areas (Weeler, Muller, 1986).

In contrast to the growth pole theory, Friedmann divides the spatial system into environment-center, defining development as a discontinuous and inventive process. Central areas are considered to be organized systems with high developmental capacity while environmental areas are subsystems with any development determined by, and dependent on, the central areas (Friedmann, 1972). In other words, in this theory, the center is considered as the development hub (Clark, 2000). Regional disparities may engender redistributive conflicts, which crowd out good government, but regional and intra-regional disparities are often driven by processes well beyond the responsibility and control of individual regions. Regional disparities may be enhanced by institutions of good governance (e.g., fiscal decentralization) and efficiency-enhancing policies (e.g., trade liberalization), while they may also be amplified 
by positive outcomes at different spatial scales, such as processes of agglomeration (LópezBazo et al., 2014).

Experiences of regional development vary between countries. For example, in South Korea, regional development problems include urban unilateralism, forgotten rural areas, urban and rural imbalances, uncontrolled migration to urban areas, resource concentration in some areas, urban growth issues, persistent poverty, the entry of multi-national companies, and new colonialism. In China, some of its regional development issues include more participation needed during decision-making processes at the local level of planning, more regional autonomy, and problems in the development process due to international forces (Misra and Bhooshan, 1981). Also in China, regional differences exist in gross domestic product (GDP), and household real per capita income between urban and rural populations, as well as spatial differences in capital distribution and production efficiency and in human resources (Zhao, 2000). In Scandinavian countries, regional development formed against a backdrop of quick industrial growth in some cities. Whereas, in the Netherlands, there are strong regional differences in productivity between industrial cities, the famous ports and other regions (Eshkevari, 2003).

In Iran, the economy is characterized by development that has led to an uneven spatial pattern of economic activities. The history of regional imbalances in Iran can be traced back to national development plans. It was hoped that the Constitutional Revolution would inaugurate a new era of independence from the great powers, but these hopes ended when, under the AngloRussian Agreement of 1907, Britain and Russia agreed to divide Iran into spheres of influenceIn the fourth development program, the gaps in the development process between the provinces, and undesirable impacts related to this, forced the government to pay attention to regional imbalances. This led to the creation of executive decentralized institutions and local decision-making in provinces, as well as large-scale investment in industrial and agricultural growth poles in those provinces and regions with sufficient resources. The central provinces of Tehran, Isfahan, and Khorasan and the second rank provinces of Gilan and Kermanshah were considered. The fifth program gave consideration to regional differences.

The new policy for regional development paid more attention to agriculture and investment in undeveloped areas. However, it should be noted that the issue of policies tackling regional differences, in what was an extreme centralist system, were not necessarily successful (Eshkevari, 2003).

\section{RESEARCH APPROACH}

Applied developmental research is the method used in the study and a combination of documentary and survey methods were utilized. Data were gathered through questionnaires and the Delphi technique was used to analyze the data. Questionnaires were completed in two stages by planning and development experts who were in charge of developmental issues. The aim of the research was to recognize and analyze those factors contributing to the imbalances in Iran. The cross-impact matrix method was then used to analyze data in order to evaluate the impact of factors on each other, and through the use of appropriate software, MicMac, the key factors in the creation of regional imbalances were recognized. After enumerating software output and studying matrix compatibility, the obtained variables are considered the most effective factors in this study and the definitive optimal answer to the problem as well as a basis for evaluating multi-criteria decision-making methods. It should be noted that the direct impact of the key factors has been extracted from the matrix output, as shown in Figure 1 (Godet, 2003). 


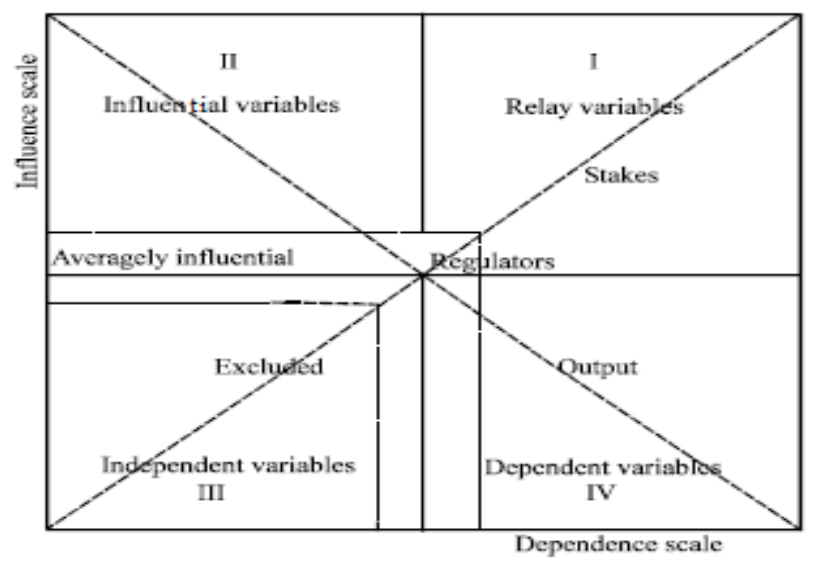

Figure 1: The status and conditions of risk variables (key factors) in the MicMac analysis Source: Hsiu-Yuan Hu, 2009

\section{ANALYSIS AND FINDINGS}

In this study, and according to extensive surveys and available background information, the causes for these regional imbalances originated from 49 factors which have been categorized into four groups, as detailed in Table (1) that have been identified as the factors contributing to regional imbalances and have been extracted and analyzed using MicMac software. The matrix dimensions are $49 \times 49$ arranged into four groups.

Table 1: Classification of effective indicators in regional development

\begin{tabular}{|c|c|c|}
\hline Classification & Indicators & Group \\
\hline $\begin{array}{l}\text { Field proportionality(1), direct access to the sea(2), Settlement patterns(3), land } \\
\text { use(4), sensitive and valuable ecosystems(5), Land constraints(6), physical } \\
\text { model of the spatial organization(7), spatial interaction of plains and mountain } \\
\text { areas(8), distribution of activities in space(9), activities' adaptability to the } \\
\text { capabilities of the environment(10), environmental capabilities(11), topographic } \\
\text { diversity(12) }\end{array}$ & $\begin{array}{l}\text { Environmental and } \\
\text { physical indicators }\end{array}$ & 1 \\
\hline $\begin{array}{l}\text { the effects of population density on land resources(13), urbanization rate(14), } \\
\text { level of services in cities(15), ethnic and cultural diversity(16), human } \\
\text { development(17), the rate of public participation(18), social wel fare(19), } \\
\text { immigration(20) }\end{array}$ & $\begin{array}{l}\text { Social, cultural, and } \\
\text { human indicators }\end{array}$ & 2 \\
\hline $\begin{array}{l}\text { Integrated management development(21), sectoral view on planning(22), } \\
\text { resources allocation(23), project-orientedness(24), personal and momentary } \\
\text { views on regional development(25), dependence on basic resources(26), polar } \\
\text { planning and type of policy planning(27), views on drought and security in } \\
\text { peripheral regions(28), borders and peripheral regions(29), policy effects of } \\
\text { outreach documents(30), dependence on oil(31), center-orientedness of } \\
\text { services(32), subject-oriented planning(33), spatial sharing(34), relying on } \\
\text { balanced resources(35), ethnic convergence and divergence(36), } \\
\text { centralization(37), growth poles(38), single urban system (first city)(39), } \\
\text { geographical distribution of resources(40), spatial one-dimensional } \\
\text { development(41), segregation of sections(42), industrial trends(43) National } \\
\text { policies(44) }\end{array}$ & $\begin{array}{l}\text { Management and } \\
\text { planning indicators }\end{array}$ & 3 \\
\hline $\begin{array}{l}\text { Employment range(45), (network economy) interactive relations between } \\
\text { areas(46), accumulation of physical investment( } 47 \text { ), competitive advantages( } 48 \text { ), } \\
\text { interaction of economic operations beyond peripheral regions }(49)\end{array}$ & $\begin{array}{l}\text { Economic } \\
\text { indicators }\end{array}$ & 4 \\
\hline
\end{tabular}


Source: The researcher classification.

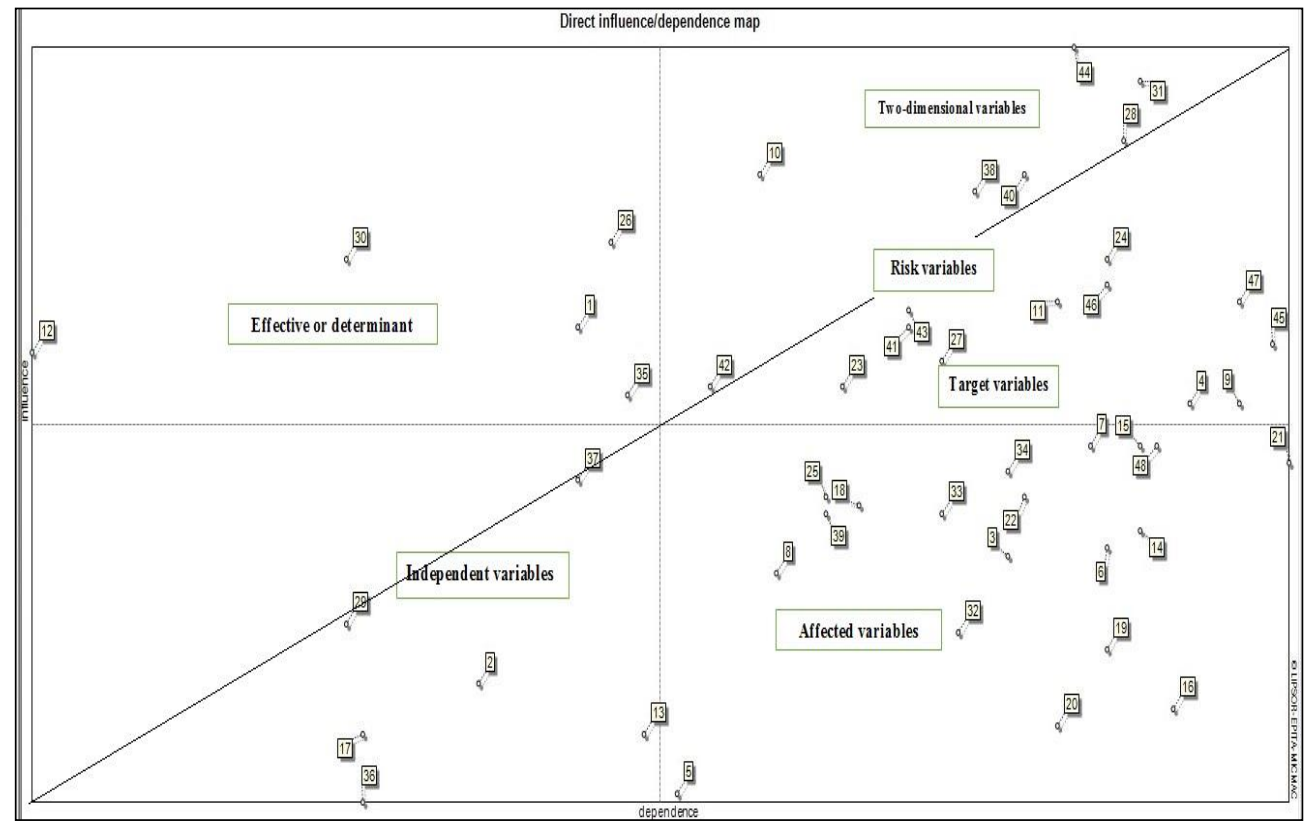

Figure 2: Variable distribution matrix and their locations on the effectiveness-impression axis in Iran Source: MICMAC analysis output.

In Figure 2, the system is known as an unstable system. The existence of factors with a high degree of effectiveness is low in the top-left of the diagram, since this location has variables in stable systems.

Nevertheless, there are several factors near this area which show their considerable impact on the whole system. These variables include "the topographic diversity of the region, dependency on oil through governmental investment, constant and personalized attitudes toward regional development, endogeneity, and reliance on balancing sources". These variables are the most important effective factors in regional imbalances, which play a much higher role in making regional balances or imbalances.

Risk variables, are located near the diameter of the south-east area of the diagram and have a very high probability of becoming key system actors. These variables include the following: "sectoral view on planning, polar planning and type of policy planning, center-orientedness of services, policy effects of outreach documents, growth poles , geographical distribution of resources, spatial one-dimensional development, industrial trends". Risk variables can mainly be considered as the variables related to planning and managerial factors.

Target variables, are located under the north-east diameter of the plane. These variables are related to how the system could evolve in the future, and indicate the possible targets of a system. By making some changes to these variables, system evolution will be achieved according to plans and targets. The target variables mainly involve the economic variables. It should be noted that the purpose behind promoting the economic variables is to reduce regional imbalances in Iran. These variables include the following:

"distribution of activities in space, environmental capabilities, resources allocation, dependence on basic resources, views on drought and security in peripheral regions, Employment range , network economy, accumulation of physical investment, interaction of economic operations beyond peripheral regions." 
Social issues are given less consideration. In other words, in development planning, the main target is economic issues, and system efficiency can be achieved through an analysis of the economic issues and by identifying the strength and weakness points.

The affected variables. are located in the south-east area of the diagram and can be called result variables. These variables are strongly affected by the system but have a low-degree of impact on the system. These variables include the following: "center-orientedness of services, Field proportionality, Settlement patterns, physical model of the spatial organization, spatial interaction of plains and mountain areas, the effects of population density on land resources, level of services in cities, human development, the rate of public participation, social wel fare, immigration, Integrated management development, project-orientedness, center-orientedness of services, subject-oriented planning, single urban system (first city), competitive advantages".

These indicators are related to improvement of the social situation, social communication, and promotion of the quality of life, which are dimensions on the quality of life index.

Independent variables, have low effectiveness and impression. They are located in the south-west of the diagram. Due to the unstable nature of the system, it appears that some of these variables have a system output nature and should be called independent output variables. These variables include the following: "ethnic and cultural diversity, direct access to the sea, sensitive and valuable ecosystems, Land constraints, borders and peripheral regions, ethnic convergence and divergence, centralization".

According to the results the experts, and Figure 2 and the analysis of MicMac, among 49 studied factors in this study, some have been selected as effective factors with regard to regional imbalances. These variables in Iran include the following (Table 2).

Table 2: The main effective factors (direct and indirect) and the final selection

\begin{tabular}{||l|l|l||}
\hline \multicolumn{1}{|c|}{ Key factors (Indirect effects) } & \multicolumn{1}{|c|}{ Key factors (Direct effects) } & Ranl \\
\hline Immigration & Spatial planning system & 1 \\
\hline Network economy & Attention to national documents & 2 \\
\hline Distribution of activities in space & Polar planning and type of policy planning & 3 \\
\hline Physical model of the spatial organization & $\begin{array}{l}\text { The activities compatibility with } \\
\text { environmental capabilities }\end{array}$ & 4 \\
\hline $\begin{array}{l}\text { Interaction of economic operation beyond } \\
\text { peripheral regions }\end{array}$ & $\begin{array}{l}\text { The geographical resource distribution } \\
\text { system }\end{array}$ & 5 \\
\hline Land use & The growth poles & 6 \\
\hline Regional cities level of service & Personalized and momentary views & 7 \\
\hline Urbanization rate & Political economy in resources allocation & 8 \\
\hline Competitive advantages & Dependency on oil & 9 \\
\hline
\end{tabular}

Source: The researcher calculations and MICMAC software analysis output.

\section{DISCUSSION}

Balanced development cannot be achieved by relying on national planning and applying irregular protection that is only short term. To achieve harmonious balance in the region, the main factors should be considered first and then all the effective factors studied in order to enhance the impact of the main factors. The infusion of petrodollars into the Iranian economy, and their distribution in terms of national development, has led to the development of some regions at the expense of others. Despite having growth potential, many of these regions, became trapped in poverty and backwardness for years, and the passage of time has not been able to resolve the 
regional development inequalities in regions. In fact, a vicious circle of underdevelopment has affected large parts of the land, even though resolving imbalances has been at the heart of development since before the Revolution and the initiation of the fourth development program.

In this study, the main factors identified in the regional inequalities in Iran are as follows:

Lack of attention to national documents. Preparation and implementation of economic development programs, based on a sectoral approach and regional attitudes, without considering national documents, have led to the occurrence and intensification of regional imbalances, the marginalization of some regions, loss of resources and regional capabilities, and land inequalities.

Non-compliance in spatial planning with sectoral planning. As the administrative system in Iran is a sectoral system, the administrative focus has led to most activities being located around the administrative centers, where population density is very high. In addition, sectoral decisions have had uncoordinated land consequences.

Moreover, since medium-term programs are prepared using a sectoral approach, the contribution of resources is based on the aims of the program and is not sourced until the main factors of the program have been decided.

The existence of the growth poles. The growth poles of the region have serious problems in terms of resource supplies, environmental protection, and efficiency, and continuity of the current development process will lead to further instability and the creation of new imbalances.

The geographical resource distribution system. According to the studies carried out, the budget and distribution of resources in Iran have been based on a sectoral approach and this has had a significant impact on development and in intensifying the regional imbalances between provinces.

Reliance on underground resources. Dependency on oil revenue has had the consequence of economic centralization with regard to national income and spending.

Compatibility of activities with the capabilities of the environment. Incompatibility between development activities in Iran and the environment is one of the most substantial and important factors. Environmental capabilities are a potential advantage for regions. However, providing some of these capabilities is impossible or not cost-effective economically in other regions.

\section{CONCLUSION}

The history of regional planning shows that many challenges need to be overcome in order to achieve desirable regional development. The results of this study demonstrate that current policies and the continuation of existing plans in Iran will only intensify destruction of the environment, thus increasing imbalances and threatening disorder not only within regions but throughout the whole country. Despite the wide range of investments and financial injections made by the government throughout Iran thus far, it has not been possible to remove the imbalances, mainly because existing agencies in the region are unable to manage the developmental mechanisms necessary to resolve the enormous issues that currently exist there. The system demands shrewd management and tools, which do not exist in the structure of the region as it is at present .

\section{SUGGESTIONS AND RECOMMENDATIONS}

\section{Short-term strategies.}

Avoiding excessive reliance on large national projects.

Avoiding concentrating development in one center to the detriment of other areas.

Identifying those areas that are a priority for development, with concentration and emphasis on mountainous areas and limiting the development and activities in the western and middle regions. 


\section{Medium-term strategies}

Strengthening international corridors or making new corridors in order to promote the national and trans-national role of regions.

Adopting enhancement and promotion of the spatial development of mountainous areas, using an environmental approach, especially in the western and central regions.

\section{Long-term strategies}

Integrating production systems under experienced management in industry, tourism, and business.

Providing an explanation for the spatial prioritization of investment (based on the experimental strategy, dispersed consolidation).

Strengthening the functional scale of the regional centers, through commercial performance and accessibility to international corridors.

Ensuring wise management of the land.

\section{Acknowledgements}

The authors would like to thank some Professors of Geography and Regional Planning who contributed to the data analysis software MicMac and for their responses to this study's questionnaire in the development of regional strategies. 


\section{REFERENCES}

[1]Bauer, R., Steiner, A.,Zaborska, Z., Schavalb, M. (2007). Good governance on the regional level in the area of regional development in slovakia,2nd Central European Conference in Regional Science - CERS, PP.68-72

[2]Clark, D. ( 2007). Urban World/Global City. London: Routledge, 2000 :9.

[3]Dupont, V. (2007). Do Geographical Agglomeration, Growth and Equity Conflict? Regional Science 86:2, pp. 193-213.

[4]Eshkevari, S. H. (2003). Analysis of Industrial Development and Regional Differences in Iran. Ph.D. Thesis. Faculty of Fine Arts, Tehran University, Iran.

[5]Friedmann, J. (1972). A General Theory of Polarized Development." In Growth Centers in Regional Economic Development, ed. N. M. Hansen (ed.),pp. 82-107. London: Macmillan.

[6]Godet, A. J., Meunier, M. F. , Roubelat, F.(2003). Structural Analysis with the MICMAC Method \& Actors' Strategy with MACTOR Method. In Project: Futures Research Methodology, eds. J. C. Glenn and T. J. Gordon, AC/UNU Millennium, V2. 0. Washington, DC: $7-10$.

[7]Hsiu-yuan, H., Shao-I, C., Tieh-Min, Y. (2009). Modified IPA for Order-Winner Criteria Improvement: A MICMAC Approach.” Journal of Applied Sciences, 9. pp. 3792-3803, doi: 10.3923/jas.2009.3792.3803.

[8]López-bazo, E., Monastiriotis V., Ramos, R. (2014) Spatial Inequalities and Economic Growth, Spatial Economic Analysis 9:2,pp.113-19, doi: 10.1080/17421772.2014.904615 .

[9]Misra, R.O., Bhooshan, B. S. (ZqtZ)(1981). Rural Development. Oxford: Oxford University Press [10]National Physical Planning Studies(2009). vol I, 5-9. Tehran: Budjet \& Plan Organization.

[11]Petrakos, G., Saratsis, Y.(2000). Regional Inequalities in Greece.” Regional Science 79:1,pp.57, doi: 10.1007/s101100050003.

[12]Ponrahono, Z., Bachok, S., Osman, M. M., Ibrahim, M., Faris Abdullah, M., Abdullah, A. (2015). Assessing the Urban and Rural Stage Bus Services Disparities in Peninsula Malaysia, Journal of the Malaysian Institute of Planners 13,pp. 65-84.

[13]Ramezani, M. E. (1997). Measuring the Development of North Khorasan Regional Planning Based Models." Urban Geography Master's thesis, Tehran University, Iran.pp. 5-6.

[14]Weeler, J. O., Muller, P. O.(1986). Economic Geography. Canada: John Wiley \& Sons, p. 68.

[15]Zhao, Y. (2000). Rural-Urban Migration in China: The Past and Present. In Chinese Rural Labor Flows, eds. L. A. West and Y. Zhao, 15-33. Berkeley, CA: Institute for East .

\section{Article history:}

- $\quad$ Received 17 October 2016

- Accepted 20 April 2017 